Volume 10, Nomor 2, November 2018, pp 149-159 Copyright (C) 2017 Jurnal Akuntansi Maranatha, Program Studi Akuntansi, Fakultas Ekonomi,

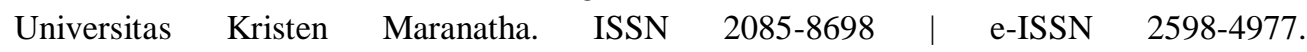
http://journal.maranatha.edu

\title{
Efektivitas Project Based Learning Model Melalui Proyek PKA-KKA Dalam Pembelajaran Audit Internal di Diklat JFA Ahli Polri
}

\author{
Mustofa Kamal \\ Widyaiswara Ahli Madya \\ Pusdiklatwas BPKP, Beringin II street, Pandansari, Ciawi, Bogor 16720 \\ kamalopek@gmail.com
}

\begin{abstract}
This action research aims to assess the effectiveness of internal audit learning in the education and training of internal police of the National Police through project based learning models. The project was chosen with consideration; there is a gap between the conditions of 24 training participants from the role of law enforcement (watchdog) and new roles as candidates for internal auditors (assurance and consulting). The research method uses qualitative and quantitative. The project provided in the form of "making PKA and $K K A^{\prime \prime}$ with the audit object is the police work unit in their respective regions. Learning effectiveness was assessed by trainers quantitatively, pre post test, and qualitatively, observations, and by training participants through online surveys. The results showed that there was an increase in understanding of internal audit through an increase in the average value of 36.46 from the average value of pre-test, 50.42 to the average post-test score, 86.88. While the results of the observations indicate that the internal audit learning process has been effective with evidence of the activities of PKA and KKA participants and projects that can be completed properly. On the other hand, a qualitative assessment of online participants showed that $58.3 \%$ of participants rated learning as having improved internal audit understanding. The rest assessed that interactive learning (25\%) and fun (16.7\%).
\end{abstract}

Keywords: Internal Audit, Project Based Learning Model 


\section{Pendahuluan}

Pendidikan dan pelatihan (diklat) sertifikasi jabatan fungsional auditor (JFA) bertujuan untuk meningkatkan pengetahuan, keterampilan, dan perubahan sikap/perilaku auditor pada tingkat kompetensi tertentu sesuai dengan perannya. Salah satu bagian dari kurikulum diklat JFA pembentukan ahli adalah mata diklat audit internal. Hasil belajar audit internal yang harus diraih oleh peserta adalah peserta mampu memahami dan menjelaskan audit internal. Mata diklat ini merupakan pembelajaran konsep audit internal selama 2 hari pembelajaran. Untuk meraih hasil belajar tersebut, metode pembelajaran yang ada di modul audit internal berupa ceramah, diskusi, tanya jawab dan latihan (Fahrudin, 2014).

Sementara itu, peserta diklat JFA ahli bagi Inspektorat Kepolisian Negara Republik Indonesia (POLRI) merupakan personil yang terbiasa dengan budaya kinerja watchdog dan kurang familiar dengan lingkungan audit internal. Untuk mencapai efekftivitas pembelajaran, peneliti mempertimbangkan untuk menggunakan project based learning model.

Ada beberapa penelitian sebelumnya yang membuktikan penggunaan project based learning model. Fikriyah dkk (2015) membuktikan bahwa penggunaan project based learning disertai media audio-visual tidak berpengaruh signifikan terhadap hasil belajar fisika siswa berupa keterampilan proses sains siswa SMA N 4 Jember. Sedangkan Nurfitriyanti (2016) membuktikan bahwa penerapan model pembelajaran Project based learningdapat meningkatkan kemampuan siswa dalam pemecahan masalah matematika di SMK swasta Bekasi Timur. Kemudian, Pratama dan Prasetyaningrum (2016) juga membuktikan penerapan model pembelajaran Project Based Learning berbantuan media pembelajaran pembangkit listrik mikrohidro dapat meningkatkan kemampuan berpikir kritis peserta didik dalam pembelajaran mata kuliah fisika teknik di IKIP PGRI Madiun. Beberapa penelitian diatas menunjukkan belum ada konsistensi hasil penelitian dan semua objek penelitian adalah peserta didik dalam pendidikan sekolah atau formal.

Penggunaan project based learning model dalam penelitian ini akan diterapkan dalam diklat JFA Ahli POLRI. Sehingga ada pertanyaan penelitian; bagaimana proses penerapan project based learning model dalam pembelajaran audit internal di Diklat Jfa ahli POLRI? Dan, Bagaimana efektivitas project based learning model dalam pembelajaran audit internal tersebut?.

Sedangkan tujuan penelitian ini adalah untuk menilai efektivitas project based learning model dalam pembelajaran audit internal. Hasil penelitian ini diharapkan bermanfaat bagi pengembangan metode pembelajaran audit internal dalam Diklat Jfa ahli POLRI dan pengembangan penelitian tindakan kelas di Diklat auditor internal pemerintah.

\section{Kerangka Teoritis dan Hipotesis}

\section{Model Pembelajaran "Project Based Learning"}

Model Pembelajaran adalah kerangka konseptual yang melukiskan prosedur yang sistematis dalam mengorganisasikan pengalaman belajar untuk mencapai tujuan belajar tertentu. Model pembelajaran berfungsi sebagai pedoman bagi perancang pembelajaran dan para pengajar dalam merencanakan aktivitas belajar mengajar (Sagala, 2005:175 dalam Suryadi dan Pramudia, 2016). Ada beberapa modelmodel pembelajaran orang dewasa, yaitu, experiental learning, cooperative learning, collaborative learning, self directed learning dan Project Based Learning (Suryadi dan Pramudia, 2016).

Project Based Learningmodel adalah model pembelajaran yang berasal dari gagasan John Dewey tentang konsep "Learning by doing" yaitu proses perolehan hasil belajar dengan mengerjakan tindakan- 
tindakan tertentu sesuai dengan tujuan (Grant, 2002 dalam Suryadi dan Pramudia, 2016). Model ini dapat digunakan sebagai sebuah model pembelajaran untuk mengembangkan kemampuan peserta didik dalam membuat perencanaan, berkomunikasi, menyelesaikan masalah dan membuat keputusan yang tepat dari masalah yang dihadapi (Nurfitriyanti, 2015).

Dalam model ini, peserta didik juga dituntut melakukan eksplorasi, penilaian, interpretasi, sintesis, dan informasi untuk menghasilkan berbagai bentuk hasil belajar. Pendidik hanya berperan sebagai fasilitator (Pratama dan Prasetyaningrum, 2016). Peserta didik dapat dibagi dalam kelompok untuk menyelesaikan proyek yang menarik dan pilihan peserta didik sendiri (Suryadi dan Pramudia, 2016). Dengan keterlibatan dalam penyelesaian projek, peserta dapat menemukan masalah-masalah yang harus ditangani yang bertujuan untuk membangun dan menyajikan produk akhir sebagai respon terhadap pertanyaan. Ada 3 prinsip konstruktivistik dalam penerapan Project Based Learningmodel, yaitu; pembelajaran berdasarkan konteks yang spesifik, peserta dilibatkan secara aktif dan peserta mencapai apa yang dituju melalui interaksi sosial dan berbagi pengetahuan serta pengalaman (Abdulhak, 2016).

\section{Program Kerja Audit (PKA) dan Kertas Kerja Audit (KKA)}

Auditor harus mengikuti Standar Audit dalam segala pekerjaan audit intern yang dianggap material agar pekerjaan auditor dapat dievaluasi. Salah satu bagian dari standar pelaksanaan assuranceuntuk auditor internal pemerintah indonesia (AIPI) adalah auditor harus merencanakan audit dan pelaksanaan pengujian bukti (Putro, 2014).

Penyusunan rencana audit bermanfaat untuk menjamin bahwa tujuan audit tercapai secara berkualitas, ekonomis, efisien dan efektif. Dalam merencanakan audit, auditor menetapkan sasaran, ruang lingkup, metodologi, dan alokasi sumber daya. Salah satu dokumen perencanaan audit adalah program kerja audit (PKA).PKA merupakan rancangan prosedur dan teknik audit yang disusun secara sistematis yang harus diikuti/dilaksanakan oleh auditor dalam kegiatan audit untuk mencapai tujuan audit. PKA akan menjadi guidance bagi auditor (Kamal, 2012).

Setiap instansi atau organisasi pengawasan/audit dapat membuat/memiliki contoh format PKA (gambar 1)tersendiri. Namun, isi PKA secara umum adalah sama,memuat informasi prosedur audit, dilaksanakan oleh, waktu yang diperlukan, dan nomor Kertas Kerja Audit (Fahrudin, 2014).

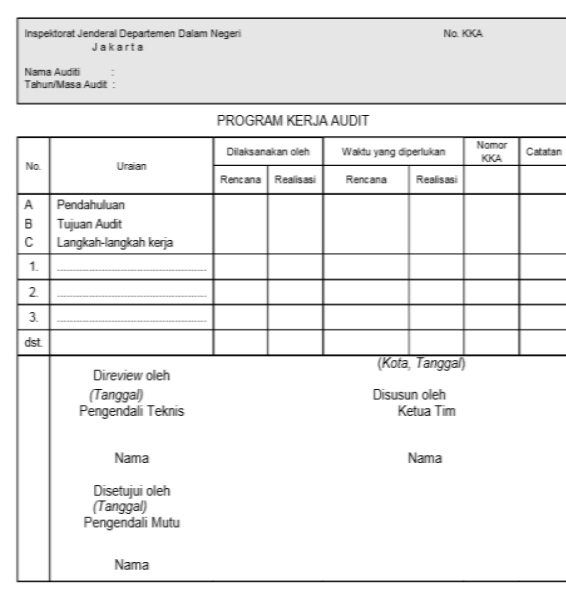

\section{Gambar 1 Contoh Format PKA Sumber : Fahrudin, 2014}

Pada tahap pelaksanaan kegiatan assurance dilakukan pengujian yang telah direncanakan dalam PKA pada tahap perencanaan. Dalam setiap pengujian yang dilakukan, hasilnya didokumentasikan ke dalam kertas kerja audit (KKA). KKA adalah catatan (dokumentasi) yang dibuat oleh auditor mengenai bukti-bukti yang dikumpulkan,berbagai teknik dan prosedur audit yang diterapkan, serta simpulansimpulan yang dibuat selama melakukan audit (Fahrudin, 2014). 


\section{Penelitian tindakan (Action Research)}

Penelitian tindakan atau Action Research merupakan metode yang digunakan dalam penelitian bidang sosial, yang menggunakan refleksi diri peserta yang terlibat dalam aktivitas di sebuah situasi tertentu (yang diteliti) dan bertujuan untuk melakukan perbaikan dalam berbagai aspek. Action Research berbeda dengan jenis riset empirisme. Masalah pengambilan populasi atau sampel dan generalisasi (salah satu ciri utama riset empiris) tidak dipersoalkan dan fokus pemberian saran pemecahan masalah (LAN, 2007).

Penelitian tindakan memiliki dua tujuan pokok, yaitu meningkatkan (improve) dan melibatkan (involve). Improve maksudnya, meningkatkan bidang praktik, meningkatkan pemahaman praktik yang dilakukan oleh praktisi, dan meningkatkan situasi tempat praktik dilaksanakan. Sedangkan involve berarti, melibatkan pihak-pihak yang terkait (idtesis, 2012).

\section{Metode Penelitian}

Penelitian ini merupakan penelitian tindakan. Metode penelititan yang digunakan adalah kualitatif dan kuantitatif. Data yang digunakan penelitian kualitatif adalah data primer dan sekunder. Data primer berupa, antara lain, data verbal dari informan yang berkenaan dengan penelitian. Data sekunder berupa data yang diperoleh dari dokumen grafis dan lain-lain yang dapat memperkaya data primer. Sedangkan penelitian kuantitatif menuntut penggunaan angka, mulai dari pengumpulan data, penafsiran dan penampilan hasilnya. Analisis data dengan rumus statistik, dapat juga hanya statistik sederhana dalam bentuk rerata, simpangan baku, tabulasi silang, tabel, bagan dan grafik (Arikunto, 2014).

Prosedur penelitian tindakan merupakan sebuah siklus yang terdiri dari perencanaan, pengambilan tindakan, pengamatan dan refleksi (LAN 2007).
Gambar 2 menunjukkan siklus penelitian tindakan. Tahap awal berupa perencanaan dan tahap terakhir berupa refleksi untuk menilai efektivitas pembelajaran dan menjadi pertimbangan penting dalam perbaikan dan pengembangan penelitian tindakan berikutnya.

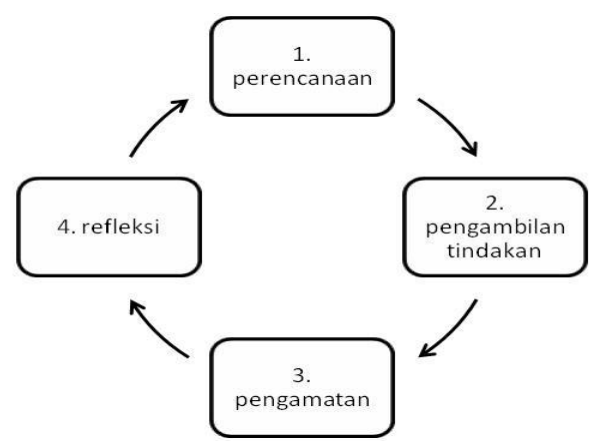

\section{Gambar 2 Penelitian Tindakan Sumber: LAN 2007}

Objek penelitiannya adalah 24 peserta Diklat Jfa ahli POLRI, di Pusdiklatwas BPKP Bogor. Pembelajaran audit internal berlangsung selama 2 hari, tanggal 28 dan 30 April 2018. Ada 2 aspek yang akan diamati, berupa; aktivitas dan pemahaman/penguasaan kompetensi teknis peserta. 
Tabel 1

Tahap Penelitian Tindakan

\begin{tabular}{|c|c|}
\hline Tahapan & Langkah Pelaksanaan \\
\hline Perencanaan & $\begin{array}{l}\text { 1. Pemberitahuan projek yang } \\
\text { harus dibuat } \\
\text { 2. Pembagian projek yang } \\
\text { harus dikerjakan oleh setiap } \\
\text { peserta } \\
\text { 3. Pemberian ketentuan } \\
\text { pembuatan projek }\end{array}$ \\
\hline Tindakan & $\begin{array}{l}\text { 4. Pembuatan projek oleh } \\
\text { peserta } \\
\text { 5. Pengumpulan hasil projek }\end{array}$ \\
\hline Pengamatan & $\begin{array}{llr}\text { 6. } & \begin{array}{l}\text { Aktivitas, sikap dan } \\
\text { perilaku peserta } \\
\text { pembuatan projek }\end{array} \\
\text { 7. } & \begin{array}{l}\text { Pemahaman } \\
\text { penguasaan } \\
\text { teknis peserta }\end{array}\end{array}$ \\
\hline Refleksi & $\begin{array}{l}\text { 8. } \begin{array}{l}\text { Efektivitas pembelajaran } \\
\text { project based learning } \\
\text { model }\end{array} \\
\text { 9. } \begin{array}{l}\text { Pendapat dan saran peserta } \\
\text { atas pembelajaran }\end{array}\end{array}$ \\
\hline
\end{tabular}

Sumber: diolah LAN, 2007 dan

Suharsono, 2015

\section{Hasil Penelitian dan Pembahasan}

\section{Perencanaan}

Widyaiswara menyampaikan penugasan projek yang harus dibuat berupa "Penyusunan PKA dan KKA. Penugasan dikerjakan individu dengan pembagian tugas sesuai dengan tujuan audit masingmasing (lampiran 1). Mekanisme penyelesaian projek disampaikan kepada peserta dengan urutan sebagai berikut:

- Hari pertama, tanggal 28 April 2018,adapre-test audit internal (lampiran 2) dan pembelajaran konsep audit internal, termasuk latihan penyusunan PKA dan KKA (lampiran 3) di kelas.

- Hari kedua, setiap peserta harus hadir di lokasi projek (lampiran 1) pada tanggal 30 April 2018 pukul 08.00 dan mengerjakan projek penyusunan PKA dan KKA secara mandiri. Di akhir penyelesaian projek, ada laporan pelaksanaan projek PKA-KKA yang harus dibuat sesuai format (lampiran 4) dan ada post-test audit internal.

\section{Tindakan}

\section{Pembuatan Projek PKA KKA}

- Hari pertama, peserta mengerjakan pretest audit internal, mengikuti pembelajaran audit internal dan mengerjakan serta diskusi latihan penyusunan PKA dan KKA di kelas dengan bimbingan trainer.

- Hari kedua, setiap peserta hadir di lokasi projek pada tanggal 30 April 2018 pukul 08.00 dan mengirim pemberitahuan ke widyaiswara/trainer secara online.

- Peserta menyampaika nmaksud dan tujuan penugasan ke kepala satuan kerja, tempat projek dan menyampaikan kebutuhan dokumen yang harus dilengkapi oleh objek audit

- Peserta menyusun PKA dan melaksanakan teknik audit sesuai langkah kerja audit yang ada di PKA dan menyusun KKA-nya.

- Di akhir penyelesaian tugas, peserta menyusun laporan penyusunan PKA KKA dan diemail ke alamat kamalopek@gmail.com_beserta lampiran berupa hasil projek PKAKKA

- Peserta mengerjakan post test audit internal pada pukul 16.30 secara online.

\section{Pengumpulan hasil projek}

Hasil projek berupa soft file-microsoft excel PKA-KKA dan laporan penyusunannya diemail pada tanggal 30 april 2018 (gambar 3). 


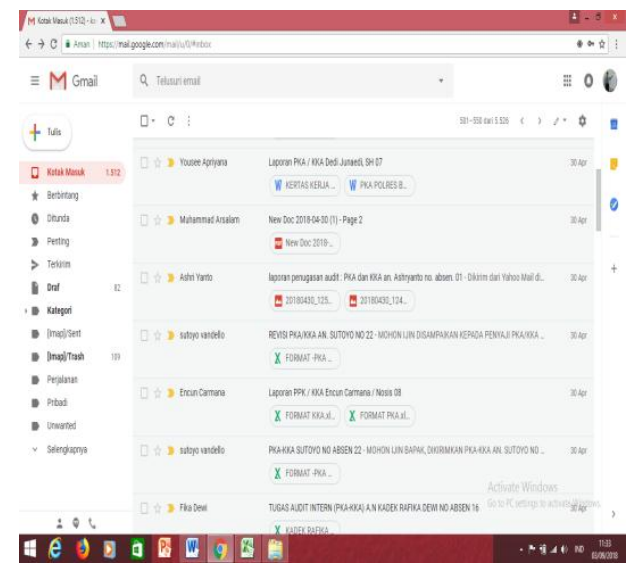

Gambar 3

\section{Screenshot Dari Penerimaan Hasil Projek Dari Peserta Sumber: kamalopek@gmail.com}

\section{Pengamatan}

Aktivitas, sikap dan perilaku peserta saat pembuatan projek

Observasi terbuka (LAN, 2007) dilaksanakan widyaiswara atas aktivitas, sikap dan perilaku peserta saat pembelajaran di kelas dan saat pembuatan projek. Hasilnya menunjukkan bahwa peserta diklat aktif dalam pembelajaran di kelas dan bersemangat dalam pelaksanaan tugas projek penyusunan PKA-KKA.

Sikap peserta sangat baik dalam merespon tugas melalui penggunaan gadget, laptop dan jaringan. Widyaiswara/trainer melihat dan menilai mayoritas peserta berperilaku kondusif dalam pembelajaran, yaitu tidak mengantuk, tidak keluar masuk ruangan tanpa tujuan saat di kelas. Sedangkan, saat pengerjaan projek PKA-KKA di lokasi satker masing-masing, peserta juga aktif dan bersemangat menyelesaikan tugas PKA-KKA.

\section{Pemahaman dan penguasaan materi pembelajaran audit internal}

Pengamatan atas pemahaman dan penguasaan materi pembelajaran dilakukan pada aspek kemampuan peserta dalam 154 memahami audit internal. Pengamatan atas proses "pengambilan tindakan oleh peserta" menunjukkan bahwa peserta telah paham audit internal melalui praktik secara langsung penyusunan PKA-KKA dengan objek audit di masing-masing satuan kerjanya.

Hal tersebut mencerminkan "project based learning model" berupa projek penyusunan PKA-KKA mendukung pemahaman peserta atas audit internal. Peserta secara langsung mampu meningkat kompetensi pengetahuan dan ketrampilannya melalui praktik perencanaan audit berupa penyusunan PKA dan praktik pelaksanaan audit internal berupa penyusunan KKA sesuai langkah kerja audit yang ada di PKA.

\section{Refleksi}

Refleksi merupakan pengkajian tujuan sementara dan untuk menentukan tindak lanjut dalam rangka mencapai tujuan pembelajaran (LAN, 2007). Untuk itu, penerapan project based learning model perlu dinilai efektivitasnya.

\section{Efektivitas pembelajaran dengan project based learning model}

Berdasarkan hasil pengamatan diatas, penerapan project based learning berupa penyusunan PKA-KKA telah efektif. Poin penting yang menjadi faktor efektivitas pembelajaran ini adalah kesesuaian projek dengan ciri/karakter personil POLRI yang cenderung aktif dan dinamis. Disamping itu, secara kuantitatif mayoritas peserta meningkat nilai pre-post test-nya (gambar 4), yaitu rata-rata peningkatan nilai preposttest sebesar 36,46 , dari rata-rata nilai pretest sebesar 50,42 ke rata-rata nilai posttest sebesar 86,88 (Lampiran 5). 


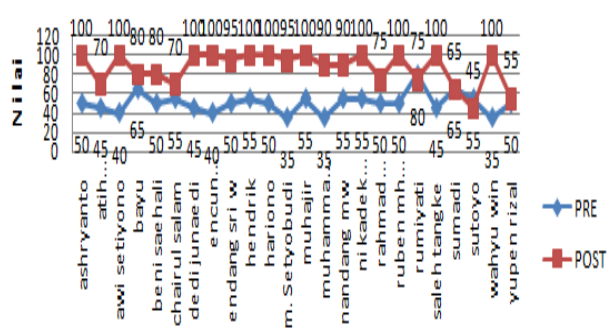

Gambar 4

Hasil Pre-Post Test Audit Internal JFA Ahli POLRI

Sumber: Diolah Dari Hasil Pre Post Test Audit Internal Asryanto dkk, 2018

Pendapat dan saran perbaikan pembelajaran

Efektivitas pembelajaran seyogyanya juga perlu dikonfirmasi kepada peserta diklat. Untuk itu, kuesioner terbuka (Sardin dan hilmi, 2016)disusun oleh widyaiswara dalam google form. Peserta diberi kesempatan untuk mengisi survai setelah pembelajaran. Untuk menjaga objektivitas penilaian maka isian survai tanpa penyebutan nama peserta.

Ada 2 pertanyaan berupa pendapat dan saran. Pertanyaan pertama; menurut pendapat Anda, bagaimana proses pembelajaran mata diklat audit internal melalui projek penyusunan PKA-KKA; apakah pembelajaran

menyenangkan/menarik, kreatif, bermanfaat, interaktif dan mudah diingat dan atau mendukung pemahaman audit internal?. Sedangkan pertanyaan kedua; apa saran anda untuk perbaikan/peningkatan efektivitas pembelajaran audit internal di masa yang akan datang.

Hasil survei menunjukkan bahwa semua peserta (100\% atau 24 orang) telah memanfaatkan media ini (Lampiran 6). Komposisi pendapat peserta atas efektivitas pembelajaran audit internal melalui projek penyusunan PKA-KKA terdiri dari 58,3\% peserta berpendapat pembelajaran telah meningkatkan pemahaman audit internal, $25 \%$ peserta berpendapat pembelajaran interaktif dan $16,7 \%$ berpendapat pembelajaran berjalan menyenangkan (gambar 5).

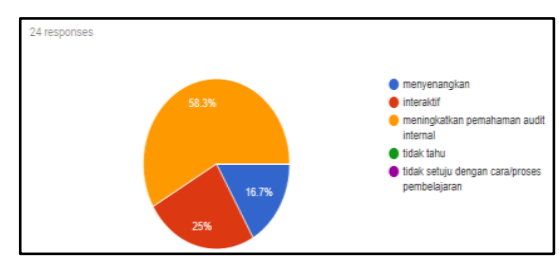

\section{Gambar 5 \\ Pendapat Peserta Atas Efektivitas \\ Pembelajaran Audit Internal Sumber: Google Form Responses, 2018}

Sementara itu, peserta juga memberikan saran yang dapat dikelompokkkan dalam 4 kategori saran (gambar 6). Yang tertinggi berupa kategori saran "sudah baik/bagus dipertahankan" sebanyak $50 \%$ atau 12 peserta. selanjutnya berturut-turut; $29,17 \%$ memberi saran "praktik berkelompok secara langsung dan refleksi materi ditambah, $16,67 \%$ jam pelajaran ditambah dan $4,17 \%$ modul perlu diupdate dengan contoh terkini dan nyata.

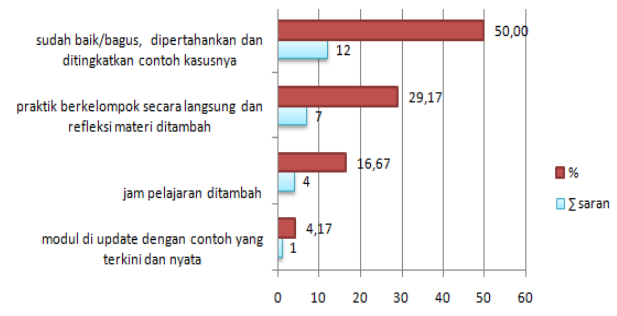

Gambar 6

Saran Peserta Untuk Pembelajaran

Audit Internal

Sumber: Google Form Responses, 2018

\section{Simpulan dan Saran}

Penerapan project based learning model dalam pembelajaran audit internal dalam Diklat Jfa ahli POLRI dapat diterapkan 
melalui projek penyusunan PKA-KKA. Penerapan model tersebut dilakukan dengan sekuen; peserta diberi projek untuk setiap peserta, pemberian ketentuan pembuatan projek, pengumpulan hasil projek dan penilaian efektivitas projek sesuai tujuan pembelajaran. Hasil penilitian tindakan menunjukkan bahwa pembelajaran audit internal telah efektif baik secara kuantitatif maupun secara kualitatif.

Peningkatan pemahaman audit internal secara kuantitatif dibuktikan melalui peningkatan nilai rata-rata yaitu sebesar 36,46 dari nilai rata-rata pre test, 50,42 ke nilai rata-rata post test, 86,88 . Sedangkan secara kualitatif, hasil pengamatan trainer menunjukkan bahwa proses pembelajaran audit internal dengan project based learning model telah efektif terbukti dari aktivitas peserta diklat dan projek PKA dan KKA dapat diselesaikan dengan baik.

Di sisi lain, penilaian secara kualitatif dari peserta melalui survai online menunjukkan bahwa $58,3 \%$ peserta menilai pembelajaran telah meningkatkan pemahaman internal audit, $25 \%$ peserta menilai pembelajaran interaktif dan $16,7 \%$ peserta menilai pembelajaran menyenangkan. Hasil ini mendukung penelitian dari Pratama dan Prasetyaningrum (2016) yang membuktikan bahwa penggunaan project based learning modelmeningkatkan hasil pembelajaran peserta didik.

Hasil penelitian ini juga dapat digunakan untuk mengembangkan atau memperbaharui metode pembelajaran audit internal agar efektivitas pembelajaran dapat dipertahankan dan ditingkatkan. Saran dari para peserta diklat JFA ahli POLRI dapat digunakan, yaitu ada praktik berkelompok secara langsung, tambah refleksi materi dan modul perlu diupdate dengan contoh terkini dan nyata.

\section{Daftar Pustaka}

Abdulhak Ishak, 2016,Konsep New Method Adult Learning, Modul 5, Diklat New Adult Learning, Kerjasama Departemen Pendidikan Luar Sekolah Fakultas Ilmu Pendidikan Universitas Pendidikan Indonesia dan Pusdiklatwas BPKP, Bandung

Arikunto Suharsimi, 2014,Prosedur Penelitian; Suatu Pendekatan Praktik, PT Rineka Cipta, Jakarta

Fahrudin M, 2014,Audit Internal, Modul Diklat Pembentukan Jabatan Fungsional Auditor (JFA) tingkat Ahli, BPKP, Pusdiklatwas BPKP, Bogor

Fikriyah Musyriatul, Indrawati, Gani Agus Abdul, 2015,Model pembelajaran berbasis proyek (project based learning) disertai media audiovisual dalam pembelajaran fisika di SMAN 4 JEMBER, Jurnal Pembelajaran Fisika, Vol. 4 No.2, September 2015, hal $181-186$

idtesis, 2012,Metode Penelitian Tindakan (Action Research), idtesis.com, 2012 diakses dari https://idtesis.com/metodepenelitian-tindakan-actionresearch1/ pada 16 Maret 2018

Kamal Mustofa, 2012,Teknik Penyusunan $P K A, \quad$ artikel di; http://pusdiklatwas.bpkp.go.id/asset/ files/post/a_74/Teknik_penyusunan_ PKA.pdf, Pusdiklatwas BPKP, Bogor

LAN, 2007, Penelitian Tindakan Kelas, Modul Diklat Calon Widyaiswara, LAN RI, Jakarta

Nurfitriyanti Maya, 2016,Model pembelajaran project based learning terhadap kemampuan pemecahan masalah matematika, Jurnal Formatif 6(2): 149-160, 2016 ISSN: 2088-351X

Pratama Hendrik, Prastyaningrum Ihtiari, 2016,Pengaruh model pembelajaran 
project based learning berbantuan media pembelajaran pembangkit listrik tenaga mikrohidro terhadap kemampuan berpikir kritis, Jurnal Penelitian Fisika dan Aplikasinya (JPFA) Vol 6, No 2, Desember 2016, p-ISSN: 2087-9946, e-ISSN: 2477-1775,

http://journal.unesa.ac.id/index.php/j pfa

Putro R Mauro Nugroho, 2014,Kode Etik dan Standar Audit Intern, Modul Diklat Pembentukan Jabatan Fungsional Auditor (JFA) tingkat Ahli, BPKP, Pusdiklatwas BPKP, Bogor

Sardin dan Hilmi Muhamad Irfan, 2016,Penerapan Metode Problem Based Learning dalam Evaluasi Pembelajaran Orang Dewasa, Modul 14, Diklat New Adult Learning, Kerjasama Departemen Pendidikan Luar Sekolah Fakultas Ilmu Pendidikan Universitas Pendidikan Indonesia dan Pusdiklatwas BPKP, Bandung

Suharsono Agus, 2015,pengembangan metode pembelajaran kompetensi non teknis planning and organizing pegawai direktorat jenderal pajak dengan permainan sundamanda, Simposium Pendidikan Tahun 2015, Jakarta

Suryadi Ace dan Pramudia Joni Rahmat, 2016,Model-model Pembelajaran Orang Dewasa, Modul 8, Diklat New Adult Learning, Kerjasama Departemen Pendidikan Luar Sekolah Fakultas Ilmu Pendidikan Universitas Pendidikan Indonesia dan Pusdiklatwas BPKP, Bandung

\section{Lampiran}

\section{Lampiran 1}
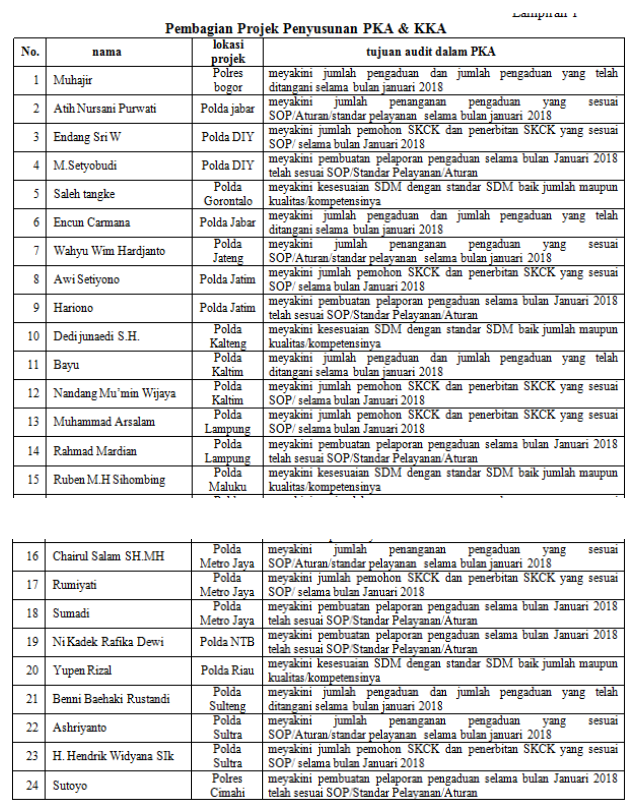

\section{Lampiran 2}

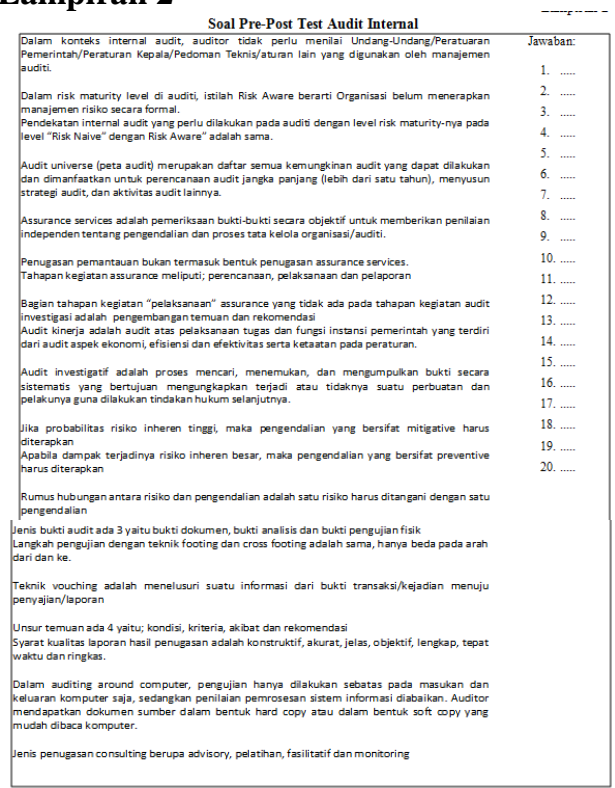




\section{Lampiran 3}

Latihan Penyusunan PKA KKA

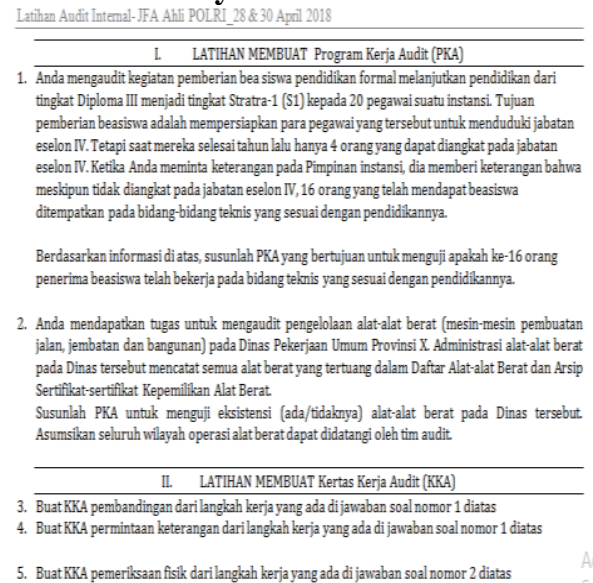

\section{Lampiran 4}

\section{Format Laporan Pelaksanaan Tugas Audit Internal}

\section{: Laporan Pelaksanaan Tugas "Audit Internal"}

Kepada Yth

- Bapak Kepala Pusdiklatwas BPKP

- Bapak Kepala Bidang P3JFA

- Bapak Widyaiswara

Berdasarkan penugasan simulasi audit internal dari widyaiswara, Saya Nama

$$
\text { Jabatan }
$$

Sebagai peserta diklat JFA Ahli POLRI di Pusdiklatwas BPKP melaporkan bahwa saya telah melaksanakan simulasi audit internal (yang dilaksanakan pada hari; Senin, tanggal 30 April 2018) sesuai instruksi. Ada pun hasil simulasi tersebut berupa:

1. Penyusunan Program Kerja Audit (PKA) untuk audit internal dengan tujuan audit .................... di Polda/Polres/Polsek ................................ (hasil terlampir)

2. Pelaksanaan teknik audit dari langkah kerja yang ada di PKA tersebut di nomor 1.

3. Penyusunan Kertas Kerja Audit (KKA) dari pelakanaan langkah kerja audit sebagaimana tersebut di nomor 2 (hasil terlampir).

Demikian laporan ini dibuat sesuai kondisi sebenarnya

\section{Lampiran 5}

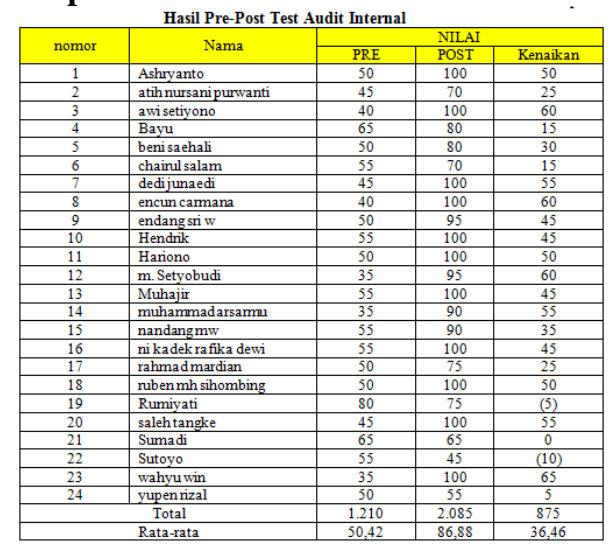

\section{Lampiran 6}

\begin{tabular}{|c|c|c|c|}
\hline Timestamp & $\begin{array}{l}\text { Respon Di Google } \\
\text { apakah anda } \\
\text { pernah mendapat } \\
\text { materi auditing } \\
\text { sebelum ikut } \\
\text { diklat JFA }\end{array}$ & $\begin{array}{c}\text { bagaimana } \\
\text { pendapat Anda } \\
\text { atas } \\
\text { pembajaran }\end{array}$ & $\begin{array}{l}\text { berikan saran atas proses pembelajaran yang menurut } \\
\text { Anda dapat meninghatkan efektivitas pembelajaran } \\
\text { materi audit internal }\end{array}$ \\
\hline $\begin{array}{l}5 / 1772018 \\
9: 59: 04\end{array}$ & TIDAK & Interalktif & 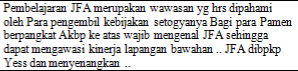 \\
\hline $\begin{array}{l}5 / 17 / 2018 \\
10: 01: 20\end{array}$ & TIDAK & menyenangkan & $\begin{array}{l}\text { Walktu pembelajaran agar ditambahkan sehingga } \\
\text { penyerapan materi pelajaran Akan lebih optimal }\end{array}$ \\
\hline $\begin{array}{l}5 / 17 / 2018 \\
10: 22: 23\end{array}$ & YA & $\begin{array}{l}\text { meningkatkan } \\
\text { pemahaman } \\
\text { audit intemal } \\
\text { and }\end{array}$ & 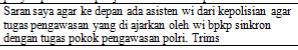 \\
\hline $\begin{array}{l}5 / 17 / 2018 \\
10: 06: 00\end{array}$ & YA & $\begin{array}{l}\text { menimgkatkan } \\
\text { pemanhaman } \\
\text { audit mitemal }\end{array}$ & $\begin{array}{l}\text { Pelu praktek audit ittern ditingkatkan, karena berkaitan } \\
\text { langsumg dg pelaks ananan tugas }\end{array}$ \\
\hline $\begin{array}{l}5 / 1772018 \\
10: 07: 18\end{array}$ & TIDAK & 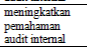 & $\begin{array}{l}\text { Agar dipertahankan dan diberkan contoh kasus } 2 \text { yg sering } \\
\text { tejijdi pada wakktu kita mengaudit khusususy di instansi } \\
\text { Polri }\end{array}$ \\
\hline $\begin{array}{l}5 / 17 / 2018 \\
10: 12: 11\end{array}$ & YA & $\begin{array}{l}\text { meningkatkan } \\
\text { pemanhaman } \\
\text { audit mitemal }\end{array}$ & 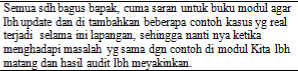 \\
\hline $\begin{array}{l}5: 17: 2018 \\
10: 14: 22\end{array}$ & YA & $\begin{array}{l}\text { meningkatkan } \\
\text { pemanhaman } \\
\text { audit mitemal }\end{array}$ & 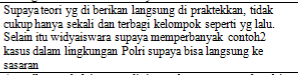 \\
\hline $\begin{array}{l}5 / 172018 \\
10: 18: 52\end{array}$ & YA & menyenangkan & 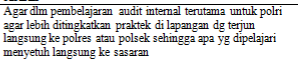 \\
\hline $\begin{array}{l}5 / 17 / 2018 \\
10: 22: 15\end{array}$ & YA & Interaklif & Sudah bagus pbm \\
\hline
\end{tabular}


Jurnal Akuntansi Maranathan Volume 10 Nomor 2, November 2018 : 149-159

\begin{tabular}{|c|c|c|c|}
\hline $\begin{array}{l}5 / 17 / 2018 \\
10: 22: 54\end{array}$ & YA & Interaktif & Sudah bagus pbm \\
\hline $\begin{array}{l}5,1722018 \\
10: 23: 52\end{array}$ & YA & Interaktif & Sudah bagus pbm \\
\hline $\begin{array}{l}5 / 172018 \\
10: 24: 12\end{array}$ & TIDAK & $\begin{array}{l}\text { meningkatkan } \\
\text { pemahaman } \\
\text { audit intenal }\end{array}$ & 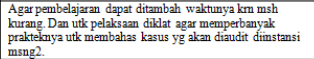 \\
\hline $\begin{array}{l}5 / 17 / 2018 \\
10: 27: 35\end{array}$ & YA & $\begin{array}{l}\text { meningkatkan } \\
\text { pemahaman } \\
\text { audit intermal }\end{array}$ & 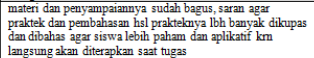 \\
\hline $\begin{array}{l}5 / 17 / 2018 \\
10: 32: 35\end{array}$ & YA & $\begin{array}{l}\text { meningkatkan } \\
\text { pemanhaman } \\
\text { auditi nintemal }\end{array}$ & 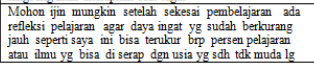 \\
\hline & & & $\begin{array}{l}\text { Cara penyampaian dari Wr sdh sangat bagus jelas.. } \\
\text { Demikian bpk terima kasith }\end{array}$ \\
\hline $\begin{array}{l}5 / 17 / 2018 \\
10: 44: 56\end{array}$ & YA & $\begin{array}{l}\text { meningkatkan } \\
\text { pemahaman } \\
\text { audit internal }\end{array}$ & $\begin{array}{l}\text { Dalam Proses Pembelajaran Materi Audit Intemal, sangat } \\
\text { mendukung pelakssanan tugas kedepan sebagai Auditor di } \\
\text { Instansi Kepolisian. }\end{array}$ \\
\hline $\begin{array}{l}5 / 17 / 2018 \\
10: 45: 16\end{array}$ & TIDAK & $\begin{array}{l}\text { meningkatkan } \\
\text { pemahaman } \\
\text { audit intemal }\end{array}$ & $\begin{array}{l}\text { Terimakasasi pembelajaran langssung praktek dg materi Polri } \\
\text { sehingga lebih memudahkan pemahaman }\end{array}$ \\
\hline $\begin{array}{l}5 / 17 / 2018 \\
10: 52: 57\end{array}$ & TIDAK & $\begin{array}{l}\text { meningkatkan } \\
\text { pemahaman } \\
\text { audit intermal }\end{array}$ & $\begin{array}{l}\text { Agar jam pelajarannya dit tambah lagi termasuk kegiatan } \\
\text { simulasinya }\end{array}$ \\
\hline $\begin{array}{l}5 / 1722018 \\
10: 59: 34\end{array}$ & YA & Interaktif & Sdh baik pbm \\
\hline $\begin{array}{l}5 / 17 / 2018 \\
11: 35: 02 \\
\end{array}$ & YA & $\begin{array}{l}\text { meningkatkan } \\
\text { pemahaman } \\
\text { audit intermal }\end{array}$ & $\begin{array}{l}\text { Waktu kegiatan sebaiknya } 5 \text { hari kejja dlm seminggu dan } \\
\text { perlu diperbanyakk kegiatan praktek lapangan dari setiap } \\
\text { pelajarnan audit. }\end{array}$ \\
\hline $\begin{array}{l}5 / 1772018 \\
11: 57: 46\end{array}$ & TIDAK & menyenangkan & AI adalah pelajaran wajib utk pembentukan auditor ahli \\
\hline $\begin{array}{l}5 / 17 / 2018 \\
12: 08: 32\end{array}$ & YA & Interalktif & Sdh suai pbm \\
\hline $\begin{array}{l}5 / 1772018 \\
13: 27: 36\end{array}$ & TIDAK & $\begin{array}{l}\text { meningkatkan } \\
\text { pemahaman } \\
\text { auditintemal }\end{array}$ & 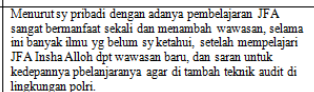 \\
\hline $\begin{array}{l}5 / 172018 \\
14: 26: 01\end{array}$ & TIDAK & $\begin{array}{l}\text { meningkatkan } \\
\text { pemahaman } \\
\text { audit intemal }\end{array}$ & 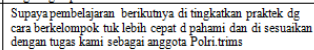 \\
\hline $\begin{array}{c}5 / 1822018 \\
9: 56: 28\end{array}$ & YA & menyenangkan & Sangat interakkif dan menyenangkan. \\
\hline
\end{tabular}

